\title{
EL TRABAJO LIBRE EN LA SOCIEDAD RURAL COLONIAL. EL CASO DE LA CHACARITA DE LOS COLEGIALES (1798-1806).
}

Gladys Perri ${ }^{(\cdot)}$

Hace más de una década se vienen realizando distintos trabajos de investigación sobre las características de la mano de obra rural en la sociedad colonial'. De acuerdo a éstos podemos decir que existen diversos tipos de explotación de la fuerza de trabajo en la campaña bonaerense, según los requerimientos de trabajo por parte de las distintas unidades productivas. Además del trabajo dentro de la unidad familiar existían dos grandes grupos que podemos diferenciarlos entre el trabajo esclavo y el trabajo libre. Entre estos podemos observar una diversidad de formas que pueden ir desde la coacción a la posible utilización de arrendatarios y agregados como mano de obra.

En este artículo analizamos específicamente a los peones libres, diferenciando dentro de esta categoría, distintos subgrupos según la forma de pago, (por jornal, mensual y a destajo), formas que se corresponden con los que conocemos como peones temporarios, permanentes, y aquellos que trabajan por tareas. Nos proponemos ver cómo se regula el trabajo y cuáles son las condiciones sociales en que se realiza el proceso de trabajo y las ca-

(•) UNLU-CONICET, beca de investigación categoría iniciación y docente de Introducción al conocimiento de la Sociedad y el Estado y de Historia Económica y Social general del CBC de la UBA.

1 Entre otros trabajos citaremos Mayo (1984, 1987, 1991 y 1995); Amaral (1987a y 1987b); Gelman (1989 y 1993a); Salvatore y Brown (1993) y Garavaglia (1995). 
racterísticas que éste adquiere en el mundo rural tardocolonial.

El caso elegido es la Chacarita de los Colegiales entre los años de 1798 y 1806, la cual estaba ubicada a dos leguas de la ciudad, por lo que es parte de una región conformada por las tierras que rodean a la ciudad -el ejido y su campaña inmediata-área de chacras y quintas especializadas en la producción cerealera, en especial la triguera, para el abasto de la ciudad ${ }^{2}$. Región donde se entrecruzan características propias de la campaña y de la ciudad dada la constante movilidad de bienes y personas entre ciudad y campaña ${ }^{3}$ y viceversa, la diversidad de producciones que coexisten, la cercania al mercado urbano, una mayor presencia de arrendatarios y esclavos, son algunas de las caracteristicas que nos lleva a repensar la idea de una oposición ciudad-campo y pensarla en una relación de complementariedad.

\section{El trabajo en la sociedad colonial}

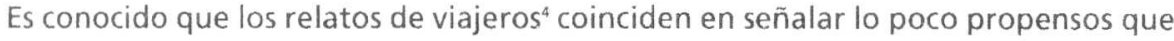
son los peones rurales hacia el trabajo y que éstos abandonan sus tareas para recorrer la campaña... Hasta aquí la visión tradicional que conocemos del gaucho.

En este artículo se analiza el trabajo en la sociedad colonial. A diferencia de otros trabajos que centraron su análisis desde la oferta y la demanda, nosotros vamos a hacer hincapié en los hábitos y comportamientos de los peones durante el proceso de trabajo. Entendiendo como proceso de trabajo no sólo el trabajo realizado sino también la forma y la posibilidad o no de que los trabajadores decidan ellos mismos que herramientas de trabajo utilizar y las formas de realizarlo ${ }^{5}$. Es decir, cuales son las condiciones sociales en que se realiza este trabajo, para ello tendremos en cuenta características propias de la mano de

\footnotetext{
2 Garavaglia (1984).
}

3 Mayo (1995: 21).

4 Entre ellos ver: Azara (1943); Concolocorvo (1946) y Gillespie (1986). A modo de ejemplo citaremos a Concolocorvo quien sostenía que los gauderíos eran consecuencia principal de la abundancia de alimentos en la campaña y "... se pasean a su albedrío por toda la campaña (...) y pasan las semanas enteras tendidos sobre un cuero, cantando y tocando. " p. 37.

5 Ver al respecto Chiaramonte (1984: 140-149). 
obra rural de la región estudiada. En este proceso de trabajo todavía no se ha operado la separación entre medios de producción y medios de subsistencia y la mano de obra rural sigue teniendo, por un lado, acceso a cierta parte de los medios de producción y subsistencia y, por otro lado, convive con el trabajo esclavo dentro de un mismo establecimiento.

Esta situación no es única del Río de la Plata ya que podemos observarla en distintas sociedades que comparten características propias del trabajo preindustrial ${ }^{6}$ entre las cuales sobresalen: a- la propiedad, de una parte al menos, de los medios de producción por ejemplo el caballo- por parte de los trabajadores lo que les permite un acceso a ciertos medios de subsistencia imprescindible como ser los alimentos?; b- en relación a la propiedad privada, ésta todavía no se conforma como forma excluyente, lo que permite la explotación de recursos comunales, como ser leña o tierras de pastore $o^{8}$ y c-la medición del tiempo del trabajo no se regula según lo que marca el reloj sino como lo marca la naturaleza"; a la vez que los usos y costumbres de cada región moldean este proceso de trabajo.

Para la campaña bonaerense podemos observar que el trabajo no escapa a estas características. La presencia de un número importante de pequeñas unidades productivas que establecen una diversidad de vínculos con la tierra -agregados, pobladores, pequeños propietarios, arrendatarios, etc.- llevó a distintos autores a hablar de una población campesina ${ }^{10}$; la movilidad de la mano de obra, tanto de un establecimiento a otro como el proceso de migraciones de distintas áreas del Virreinato hacia esta región; su capacidad de ne-

6 Entendido como el proceso anterior a la proletarización masiva como relación social dominante en las sociedades industrializadas y -a la vez-teniendo en cuenta la salvedad que realiza Thompson sobre este concepto, el cual es bastante amplio y encubre distintas relaciones sociales en el tiempo y el espacio. Thompson (1995: 32). Sobre el proceso de trabajo en una sociedad precapitalista es sugerente el análisis de Chiaramonte, quien marca para el caso de lberoamérica colonial que estamos ante una sociedad precapitalista porque todavía el proceso de trabajo no fue subsumido de manera real por el capital y porque lo dominante en esta sociedad es el capital mercantil. Chiaramonte (1984).

7 lbídem.: 56, Hobsbawm (1977 y 1987).

8 Thompson (1995).

9 Ibídem y Hobsbawm (1977).

10 Ver los trabajos de Garavaglia (1993) y Gelman (1992a y 1993b). Entre otros trabajos de los autores. 
gociación y resistencia, y el control que mantienen sobre parte del proceso de trabajo". De esta manera el trabajo estaba pautado y tenía sus propios tiempos, tiempos y ritmos que como vimos caracterizan al trabajo preindustrial.

En este artículo analizamos el trabajo y el salario apuntando hacia el entramado social que se teje entre los peones y quienes los emplea. Hablamos de trabajo libre. Por otra parte, el salario era pactado libremente, pero las fuentes son parcas en indicar cuales eran las condiciones, ni si el tiempo a trabajar era pactado en el momento de la contratación o en el transcurso de las actividades, sólo nos dicen: "entro a trabajar (tal día), con un salario de... " y terminan diciendo solamente: "se fue". Estos baches vamos a tratar de suplirlos, por un lado, tratando con una lectura distinta las fuentes que tenemos: tratando de entrever las "reglas" que rigen esta sociedad moldeada por la costumbre. Para ello el análisis de los Bandos Virreinales, con relación a la mano de obra, nos permite poder observar la interacción que existe entre la norma y la práctica.

En este punto es interesante analizar la normativa que parte desde el Estado CoIonial y como ésta, como toda norma legal, se apoya en un entramado social ya conformado y respetado por la sociedad. Lo aceptado como normal no necesita ser normalizado ni repetido de año en año; en cambio, la repetición de una norma, nos permite observar la brecha existente entre las prácticas socialmente aceptadas y lo normativo.

Analizamos los Bandos de los Gobernadores y Virreyes dictados entre 1743 y $1805^{12}$ en estos 58 años se dictaron 51 Bandos tendientes a normalizar y regular el trabajo del peón rural. Para la época de la cosecha -punto más álgido de la actividad triguera y que demanda una mayor cantidad de trabajadores- se dictaron 45 Bandos en los meses de diciembre o enero para compeler a los trabajadores a que se conchaben para la siega ${ }^{13}$. Con estos

11 Entendiendo como dominio del proceso de trabajo que todavía no existe una subsunción total del trabajo al capital.

12 AGN, IX, 8, 10,1; 8-10-2; 8-10-3; 8-10-4; 8-10-5; 8-10-7 y 8-10-8.

13 Las fechas en que se publican estos bandos son: 2-1-1743; 8-1-1744; 6-12-1745; 2-121746; 14-12-1750; 13-1-1752; 9-1-1753; 19-12-1753; 11-12-1754; 16-12-1755; 18-11-1756; 8-1-1760; 12-12-1760; 9-1-1762; 17-1-1764; 13-12-1766; 29-12-1767; 2-1-1769; 10-12-1769; 20-12-1771; 29$11-1773 ; 4-12-1774 ; 29-12-1775 ; 17-12-1776 ; 17-11-1777 ; 21-1-1779 ; 15-12-1780 ; 10-12-1781 ; 19-$ 12-1782; 14-1-1784; 29-12-1784; 10-1-1786; 11-12-1787; 23-12-1791; 11-12-1792; 11-12-1795; $27-$ 12-1797; 19-12-1799; 18-12-1799; 18-12-1800; 18-12-1801; 10-12-1803; 19-12-1804; 11-12-1805. 
datos hemos confeccionado el Cuadro $N^{0} 1$ donde hemos agrupado estos bandos en tres grandes grupos de medidas que se toman: a- la convocatoria a parte de la población; b- la prohibición de juegos, diversiones y venta de alcohol; y, c- la reglamentación del trabajo.

\section{La convocatoria a parte de la población}

Podemos observar que para la siega se convoca a parte de los habitantes de la ciudad. En ocho oportunidades sólo se convoca a los indios, negros y mulatos libres. En dieciocho bandos a los negros y mulatos se les suman los zapateros y sastres. A partir de 1791, aparece otro tipo de convocatoria que consiste en compeler al conchabo a todos aquellos que están viviendo en la ciudad y no están domiciliados en ella. Estas medidas están acompañarlas del cese de las actividades en los obrajes de tejas y ladrillos y de las obras públicas -cuestión que es reiterada en 30 bandos- con lo cual se puede apreciar cierta paralización por no decir total- de las actividades urbanas en los meses de enero y febrero. Estas medidas reiteradas para compeler a la mano de obra para que se conchabe en las chacras están constantemente acompañadas por el castigo -la pena- para aquellos que no las cumplan. Aquí es significativo observar que sólo en dos años, 1752 y 1792 -es decir, sólo en dos bandos sobre los 45 que se publican- ${ }^{14}$, quienes sean arrestados por no cumplir dichos bandos son enviados o entregados a los labradores que los necesiten y en 1792 se aclara que éstos trabajaran "a ración y sin sueldo"15. Para el resto de los años los castigos que se prevén en los Bandos son el destierro, los azotes, el Real Presidio, o el trabajar a ración y sin sueldo en las obras del Rey. Lo que nos lleva a pensar en la limitación de estos bandos en relación a su objetivo inmediato -conseguir peones para levantar las cosechas-, ya que no son coaccionados a trabajar para este fin sino que solucionan el problema de obtener mano de obra para las obras públicas sin que la Corona desembolse el valor de los jornales. Martínez Dougnac observó que en los meses de la cosecha no aumenta la cantidad de detenciones por vagos o por juegos, y es significativo que no se realice ninguna detención en el mes de enero. La autora concluye que estos bandos no tienen como objetivo una proletarización total sino que pretenden crear la costumbre de que los peones se conchaben en una determinada parte del año ${ }^{16}$.

14 AGN, IX, 8-10-1 y 8-10-5, respectivamente.

15 Ibídem. f178v.

16 Martínez Dougnac (1996). 


\section{La prohibición de juegos y diversiones}

Estas medidas rigen tanto para la ciudad como para la campaña. Para la primera se repite en 26 años y solamente dice que se cierren las canchas. Para la campaña la prohibición se reitera en 31 bandos y son más específicos. ¿A qué juegos en la campaña se hace referencia? Aquí encontramos un sinnúmero de ellos, como ser: juegos de canchas, de bolos y de bolas de aro, de bochas, al pato, carreras de caballos -todos ellos al aire libre-. $Y$, por otro lado, los juegos que se desarrollaban en las pulperías: naipes, dados, taba y el de banca. Las medidas van más allá de prohibir esos juegos ya que no sólo se pena a quien se encuentre jugando sino que también a quien posea algunos de los elementos de dichos juegos, como ser portar naipes, dados, etc. y, como contrapartida una multa monetaria a labradores y pulperos que permitan estos juegos.

No solamente se manda que se cierren las canchas que están dentro de las chacras para no dañar las sementeras, sino que estas medidas pretenden disciplinar a la mano de obra para que no abandone el trabajo antes que finalice la jornada. En este sentido es muy explicito el bando del 23-12-1791, el cual manifiesta:

"5. que soliendo acontecer, q.e dexando el trabajo los peones para comer al medio dia baxen al rio a pretexto de dar agua a los caballos o bañarse, y se junten en quadrillas a jugar, de q.e resultan algunas desgracias (...) y q.e no concurran todos por la tarde al trabajo, o q.e lleguen fuera de tiempo: encargo estrecham.te a los Alc.s y comisionados ronden con el mayor celo a las tales horas los margenes del rio y bosques de las barrancas (...) en q.e se junten con este fin u otro q.e no sea justo y desvaraten los juegos, quiten barajas, tabas y dados, (...) y q.e practiquen igual dilig.a con los que pusieren pato o formaren carreras; evitando por todos los medios posibles estas juntas tan perniciosas, y cuidando q.e todos trabajen. " ${ }^{17}$.

Que estas prohibiciones se repitan año tras año nos indica que estas no eran respetadas cabalmente. Es interesante destacar que estas prohibiciones también son extensi-

17 AGN, IX, 8-10-5 f. 254v. 
vas a todo el año laboral y en algunos casos se trata de reglamentar estos juegos o ponerles horarios. En 1790 en un bando para el buen gobierno se especifica que:

"8- que tampoco permitan dhos. dueños de canchas jugar

en ellas los dias de travajo: y si las tuviesen en las

Poblaciones de las Parroquias, no dejen jugar en ellas

hasta q.e se haya celebrado la Misa Mayor... "18.

Por lo visto, éste no era solamente un problema en la época de la cosecha sino que también era "sufrido" a lo largo de todo el año, y, en los días de fiesta y los domingos durante la misa.

\section{La reglamentación del trabajo}

Los distintos trabajos de investigación realizados han marcado que el jornal pagado en la época de la cosecha oscila entre 4 y 5 reales diarios para ambas márgenes del Río de la Plata' ${ }^{19}$.

Desde 1752 los Bandos intentan reducir y fijar el jornal, que se paga durante la siega, en dos reales que es el "salario corriente" ${ }^{20}$. En 1762 se fija en 3 reales, de acuerdo a como lo pide el Regidor Don Eugenio Leroc de Tejada:

"...y estas jentes aquien se obliga salir a la siega piden

por su travajo diario cinco, y seis, siendo su regular

salario de tres [en la ciudad], con que vienen a impocivilitar

por el subido precio que piden el que los conchaben (...) se

ha de servir V.E. mandar que los dhos. peones travajen y se

conchaven por solo el estipendio de tres reales..." ${ }^{21}$.

18 Ibídem. f. 134v.

19 Para la banda Oriental ver los trabajos de Perez (s/f y 1996); Gelman (1989 y 1993a); Barrán y Nahum (1989) y Perri (1994). Para la campaña bonaerense los trabajos de Mayo (1995) y Fradkin (1993) entre otros trabajos.

20 AGN, IX, 8-10-1, f.344.

21 AGN, IX, 8-10-2, f. 298-298v. En 1774 se vuelve a reiterar que el jornal debía ser de 3 reales. AGN, IX, 8-10-3, f. 60-60v. 
La contestación a este pedido va a ser que se publique el bando tal como ha sido solicitado por el Regidor. Ya para 1777, se estipula que este jornal debe ser de 4 reales y de 2 para los muchachos ${ }^{22}$. Dice textualmente la fuente:

"3. A los mejores peones que trabajen en dhas. faenas, no se les dé mas que quatro reales al dia, y a los muchachos dos reales, y lo que mas tres... "23

Y recalcamos lo que dice la fuente "a los mejores peones", el resto percibiría un jornal de tres reales. Ante esta situación resaltamos la idea de bajar el jornal que se acostumbraba pagar en la época de la cosecha, un intento de equipararlo al que se pagaba normalmente en la ciudad, pero que en la situación concreta los labradores se veían ante la necesidad de pagar un jornal más alto como recurso para atraer mano de obra.

Sobre el jornal estos bandos tienden a erradicar la costumbre de entregar adelantos por el trabajo a realizar, dice el Bando:

"8. Por ningun motivo, ni pretesto se les pague adelantado, ni puedan los peones pedirlo con la boluntariedad que acostumbran amenazando, y mas efectivamente yendose, sino les dan todo lo que piden... "24

Con lo cual observamos como actúa esta entrega de adelantos y la consideramos como una estrategia, tanto por parte de los peones como de los labradores: los primeros por percibir un salario antes de realizar el trabajo, y los segundos para poder obtener peones en una época de escasez.

También se reglamenta el pago para quienes se conchaben a destajo, a los cuales se les pagara entre 4 y 5 pesos por fanega; y se aclara específicamente que a estos no se les dará ni comida ni mate.

22 AGN, IX, 8-10-4, f. 24v. Repitiéndose lo mismo en 1784. AGN, IX, 8-10-5, f. 14v.

23 Ibidem. El subrayado es nuestro.

24 Ibídem. f. $25 \mathrm{v}$. 
En estos Bandos también se normalizan los tiempos de trabajo y descanso en la época de la cosecha. A partir del Bando del 14-11-1777 hemos confeccionado el cuadro 2 donde queda expresada la jornada ideal de trabajo la cual comenzaba a las 4 de la mañana y finalizaba una hora después de la puesta del sol. Aquí sorprende observar la cantidad de momentos de descanso que se permite a los peones durante la jornada. El Bando dice textualmente:

"4. se han de levantar a las quatro de la mañana pa beber mate, y entrar immediatamente al travajo y a la hora y media q.e esten en el, se les dará otro mate y media ora despues el almuerzo y a la ora de este otro mate $y$ de ay en adelante hasta que salgan del travajo toda la agua fria q.e quiciesen. 5. a las once y media se retiraran a la casa donde descansaran media ora, y a las doce se les dará de comer para que duerman la siesta hasta las dos que se les dispertará dandoles mate y bolveran sin demora otra vez a la faena: Alli con igual distribucion de tiempo se les serviran otros dos mates, $y$ despues toda la agua fria hasta que del todo dejen el travajo que será una ora despues de entrado el sol. "25.

Hay que destacar algo muy sugerente en esta reglamentación que es la fijación de la hora de la siesta y que cuando esta no sea permitida se les abonara a los peones un real extra ${ }^{26}$ los días de trilla "...y otros en que es preciso aprovechar el viento... "27. Esta jornada que se extendería a veinte horas diarias si le reducimos los tiempos de descanso según el cuadro $^{28}$ el tiempo efectivo de trabajo durante la siega sería de dieciséis horas.

De esta manera observamos a partir de esta diversidad de situaciones, como "el salario era una relación económica que no estaba despojada de imperativos sociales pauta-

25 AGN, IX, 8-10-4, f. 25.

26 En un trabajo anterior ya habíamos llamado la atención sobre esta costumbre en una chacra de la Banda Oriental. Perri (1994).

27 AGN, IX, 8-10-4, f. 24v.

28 Hemos adjudicado a cada tanda de mate unos quince minutos con lo cual al día los tiempos de descanso ascenderian a una hora y media más. 
dos por la costumbre" "29. Costumbres como la del mate, que se les dé comer a los peones, el adelanto de salarios, la siesta tan arraigada en la sociedad colonial y post-colonial son indicios sugerentes para analizar las relaciones tiempo/modalidad de trabajo.

Hasta aquí la normativa dictada por el estado colonial, ¿qué sucede en la realidad? Para contestar este interrogante utilizamos las fuentes de la Chacarita de los Colegiales dependiente del Real Colegio de San Carlos, entre 1798 y 1806 para analizar el trabajo y los trabajadores dentro del proceso productivo ${ }^{30}$.

\section{El trabajo y los trabajadores en la Chacarita}

En un trabajo anterior sosteníamos que la chacarita estaba muy bien equipada en relación a sus chacras vecinas, lo cual le permitía tener una estrategia de producción diversificada y orientada tanto hacia el mercado, el sólo hecho de tener galpones para almacenar trigo le permitía elegir una coyuntura favorable de precios para su venta, lo cual -a pesar que una parte, nada desdeñable, de su producción era destinada a abastecer el consumo del colegio ${ }^{31}$, la aleja del patrón del pequeño productor para convertirse en una gran

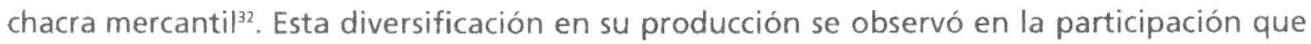
el trigo y la leña ocupan dentro de los productos que se venden en el mercado. A estas producciones hay que sumarle la existencia de una huerta, una quinta, hornos de ladrillos y tejas entre otras tantas actividades que en ella se realizaban.

Las necesidades laborales de la chacra eran cubiertas por una dotación de 22 esclavos -cantidad importante y que aumenta a partir de 1806, por compra, nacimientos y por la incorporación de los esclavos del Colegio ${ }^{33}$ - y una cantidad inestable de peones libres que

29 Fradkin (1996).

30 Sobre la chacra ver los trabajos de Fradkin (1993) y Perri (1998).

31 Sobre la participación de la chacra como abastecedora de leche y pan al Colegio ver Perri (1995).

32 Ver el trabajo de Gelman (1993a).

33 Cantidad que no pudimos establecer ya que las fuentes sólo nos dice que al cerrarse el Colegio los esclavos que allí residían -excepto tres que se quedan para servir a Choarrainpasan a la chacra. AGN, IX, 7-8-5. 
podían ser contratados por día (como jornaleros), por mes (corrido o contado) ó por tareas. Los jornaleros no sólo eran contratados para la época de la siega sino que también a lo largo del año para realizar actividades específicas.

La modalidad por mes que hemos diferenciado como mes corrido o mes contado surge de la propia fuente que analizamos. Mes corrido es el mes calendario con sus 30 dias. Por mes contado se entiende el mes efectivamente trabajado por cada peón, es decir se "cuentan" los días trabajados y al llegar a los 30 se considera que el peón "ha cumplido el mes", es así como el peón puede estar-decimos puede estar porque no sabemos con certeza donde vive- en la chacra 2, 3 y hasta 4 meses pero sólo se le contabilizan los dias efectivamente trabajados. Cuando nos referimos a trabaja por tareas, aquí no cuentan los días sino el trabajo que realiza el peón por el cual se le paga, trabajos que consisten en cavar una zanja, recolectar leña o cardo, etc.

Entre 1798 y 1806 la chacra gastó 13.189 pesos 5 reales 1 cuartillo, de los cuales la mano de obra representa el 51,4\% del total, cifra importante pero baja si lo comparamos con otras unidades productivas ${ }^{34}$. En este trabajo observábamos que prácticamente no existía una gran diferencia entre lo que la chacarita gastaba en peones que realizan distintos trabajos a lo largo de todo el año y en los peones para la siega ${ }^{35}$, esta diferencia se debe a que a lo largo del año la chacarita no sólo precisa peones para la producción triguera sino también para el resto de las actividades productivas que en ella se desarrollan, especialmente la recolección de leña.

Volvamos a los trabajadores que se conchabaron a lo largo de los nueve años estudiados $^{36}$ de los 221 peones permanentes que trabajaron en la chacra sólo el 13,1\% (29

34 Juan Carlos Garavaglia para la estancia de los Portugueses en Chascomús señala que para el período 1802-1809 los gastos en salario representaron el 62\% del total, en Garavaglia (1995). Para la chacra de la estancia de las Bacas en la Banda Oriental Gelman observa que casi el $90 \%$ de sus gastos corresponden a mano de obra, ver el cuadro 3, en Gelman (1993a: 18). Por último -para la misma chacra analizada por nosotros, en un período anterior-Raúl Fradkin marca que uno de los grandes rubros de los gastos de la chacarita corresponde a la mano de obra, en Fradkin (1993: 34).

35 Diferencia que si encontró Gelman para la chacra oriental de las Bacas. Gelman (1993a: 18).

36 En este artículo sólo vamos a hacer referencia a las conclusiones que llegamos en el trabajo ya citado. Perri (1998). 
peones) volvieron a trabajar en otros años, pero ¿cuánto tiempo de trabajo representan?, al calcular la cantidad de días trabajados por cada peón establecimos un promedio, para los 9 años, de 67,7 días. Para 1802 se observó el promedio más bajo (38 días por peón) y en 1804 el más alto (1161/2 dias por peón) A partir de estos datos hay que diferenciar dos momentos. Uno que va desde 1798 a 1804 y otro que abarca los últimos tres años. Para el primero observamos que hay una mayor cantidad de peones conchabados y que permanecen poco tiempo en la chacra, y, a partir, de 1804 baja la cantidad de peones conchabados a la vez que aumenta la cantidad de días trabajados por ellos.

En diciembre de 1801 se piden 20 prisioneros portugueses para la siega, y antes de que esta comience, los prisioneros están encargados de limpiar la laguna donde bebe el ganado ${ }^{37}$, es de destacar la excepcionalidad de este año ya que la chacra vio y utilizó la posibilidad de ampliar su dotación de peones combinando distintas formas de trabajo: el trabajo compulsivo con el trabajo asalariado. Otro elemento importante que observamos a partir de la lectura del cuadro, es que en 1802 aparece la modalidad del trabajo por tareas, tareas que se relacionan con la recolección de leña, de cardo y el zanjeo.

Los salarios percibidos por los peones de la chacra oscilan entre 6 y 7 pesos, en el único caso que se paga un salario de 5 pesos es al peón caballerizo y al peón boyero. En 1806 el salario del peón boyero aumenta a 6 pesos y el resto de los peones cobran 7 pesos mensuales, evidentemente hay una tendencia al aumento de los salarios hacia el final del período analizado ${ }^{38}$.

Según los años se observaron distintas formas de anotar la manera de pagar el salario: hay años que se paga el salario en una sola vez al mes y en otras oportunidades se otorgan adelantos y sucesivas entregas de metálico -situación que se da entre 1800 y 1804 . Estos adelantos marcan un tipo de estrategia por parte de la chacra para poder conseguir

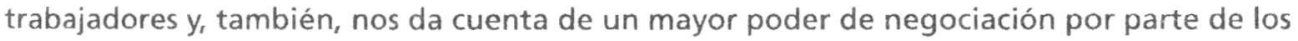
peones ya que reciben parte de su salario antes de realizar efectivamente su trabajo.

Sobre la composición del salario la fuente no incluye ninguna especificación de pa-

37 "Correspondencia del Colegio", AGN IX, 7-3-5.

38 Esta situación ya fue observada por Johnson para los trabajadores de la ciudad. Johnson (1992).

94 
gos en especie, por lo que nosotros concluimos que éstos eran pagados en plata contante y sonante. Con lo cual marcábamos la diferencia que presentaba la chacra estudiada, en relación a las estancias donde era corriente el pago en especie y plata del salario ${ }^{39}$. Esta situación nos marcó el grado de monetización que adquirió la mano de obra en el ejido ${ }^{40}$, lo que nos hace pensar en una mayor resistencia por parte de los peones en una región ávida de mano de obra, no sólo para la producción triguera, sino también para la recolección de leña y por la presencia de numerosas quintas y huertas que circundan la ciudad de Buenos Aires, es así que tenemos distintas producciones que compiten entre sí por la fuerza laboral hecho que favorece a los peones en el sentido de tener un mayor poder de negociación, lo que permitiría que este salario sea pagado íntegramente en plata.

Los peones en la chacra son retribuidos por los distintos trabajos realizados: en la zanja, en el monte, andar con las carretas, peón caballerizo y peón boyero, faenar cardo, arar, traer ganado de la estancia, en la huerta, en el charco, por reparar el "xague " y cerrar o zanjar portillos. Trabajos que un mismo peón podia realizar, lo cual nos llevo a sostener que los peones llevaban adelante una estrategia de combinar distintos tipos de trabajos con distintos tipos de remuneraciones (por día, mensual o por tareas) que les permitía poder aumentar sus ingresos.

La forma más corriente de alternar estos trabajos era la siega, la recolección de leña -trabajo a destajo- con él conchabo mensual.

\section{Los peones de la siega}

La cosecha es el momento más importante del ciclo triguero y el que insume una mayor cantidad de peones y un desembolso mayor de plata contante y sonante ya que los

39 Ver Mayo (1984); Gelman (1992b); Salvatore y Brown (1993) y Perri (1994).

40 Cabe aclarar que Mayo, Gelman y Salvatore y Brown -para la estancia de las Bacasmarcan la preferencia de los peones por cobrar en plata y la resistencia que oponen a cobrar en especie. Resistencia que termina siendo eficaz en el sentido que sólo una parte del salario es pagado en especie y el resto en plata. Situación que marcaría -según Mayo- una diferenciación en la forma de pagar el salario entre la campaña rioplatense y el Interior del Virreinato. Ver los trabajos citados en la nota anterior. 
jornales que se pagan son mucho más altos en relación a los que se pagan a lo largo de todo el año.

La siega se divide en distintas etapas, que pudimos establecerlas tomando como hilo conductor las cosechas de 1798 y 1799 . A partir de diciembre ó los primeros días de enero -según el mes en que comience la cosecha-se destinan peones para ir a buscar ganado a la estancia, para componer los galpones donde se va a almacenar el trigo y para componer la era. Las actividades se continúan según este orden: segar, engavillar, meter trigo en la era, aventarlo, trillarlo y, por último, guardarlo.

Tal como se observó para los peones permanentes también se percibió una tendencia a la baja a partir de 1804 en la cantidad de peones necesarias por día para levantar el trigo y estos comienzan a quedarse más tiempo y en algunos casos durante toda la cosecha.

Observamos que todos los peones indistintamente realizan estas actividades. Los únicos que tienen una actividad específica son el peón yeguarizo y quien dirige la trilla que en algunos años puede ser esclavo-. En 1802 tenemos una "muger asalariada " la cual cocinó para los peones al igual que al año siguiente. En 1804 tenemos a Manuel Gutierrez "muchacho" que cobra 2 reales por día y, por último, en 1806 aparece Josef Sanchez -hijo del peón Manuel Sanchez- trabajando como aguatero.

Como ya mencionamos el jornal que se pagaba en la cosecha era de 4 reales diarios $^{41}$, nuestras fuentes también nos dicen que éste jornal era costumbre en la región, tal cual lo expresa Dn Luis de Choarrain al Virrey Dn Joaquín del Pino en noviembre de 1801, en momentos que pide los prisioneros portugueses:

"...q.e el salario q.e se les de sea el de quatro reales

diarios q.e es el acostumbrado en tiempo de cosecha en años anteriores... "42

Pero parece ser que ante la escasez de mano de obra tuvieron que pagar jornales más altos de lo que la costumbre estipulaba y vemos como el jornal pasa a ser de 5 reales

41 Gelman (1993a), Fradkin (1993) y Mayo (1995).

42 AGN IX, 7-3-5, f. 298v. 
a partir de ese año.

También se observó que hay una tendencia al aumento del jornal para los últimos años.

Es interesante destacar como se medía el tiempo de trabajo en la época de la cosecha, según las actividades que se realizaran. Para 1798 y 1799 tenemos cuánto era el jornal pagado si se trabaja menos de un día. Hasta el almuerzo se paga 1 real, hasta el medio día: 2 reales y hasta más del mediodía o mediatarde: 3 reales. El jornal es de 4 reales a excepción de algunos días de trilla que pagan 5 .

En el cuadro 3 agrupamos, según los años, las formas de contabilizar el tiempo trabajado por cada peón. Esta diversidad nos marca esas características del trabajo preindustrial que señalábamos al comienzo de este trabajo. El tiempo de trabajo estaba pautado por la naturaleza.

Hay que mencionar que también en la Chacarita se observó que en los días de trilla, que son los días que los peones no pueden dormir la siesta, se les abona un real más. Igual situación sucede en 1801 cuando se trabaja en un día de fiesta como ser el primero de enero, que se compensa a los peones con un jornal de 6 reales, cuando en ese año el jornal que se pago osciló entre los 4 y 5 reales.

Con relación a los prisioneros portugueses hay que señalar que no todos trabajaron todo el tiempo que duró la cosecha e incluso uno de ellos no realizó tarea alguna. Lo que nos estaría indicando que hasta dentro del trabajo compulsivo existiría la posibilidad de negarse a realizar las tareas encomendadas.

A los jornales pagados hay que agregarles el aguardiente, los mates, bombillas y yerba que se compran para la cosecha. Además la chacra también se encarga de la comida de éstos -paga a una cocinera, además de proveer los alimentos- y en algunos años tenemos compras de quesos para el almuerzo de los peones. Vemos como esto se convertiría en un salario indirecto, ya que la chacra se encarga de la manutención de sus jornaleros en la época de la siega ${ }^{43}$.

43 Lyman Johnson marca que era normal que el almuerzo de los trabajadores sea pro- 


\section{Entre la ley y la práctica. Una aproximación a las pautas del trabajo}

Al analizar los Bandos Virreinales habíamos marcado tres grandes grupos de medidas que año tras año se repetian: la convocatoria a parte de la población de la ciudad para que se conchabe en la cosecha ante la escasez crónica de peones en esta época del año; la prohibición de todo tipo de juegos -en ciudad y campaña- y la venta de bebidas alcohólicas; y, por último, la reglamentación en torno a los tiempos del trabajo, los jornales que debían pagarse, los adelantos, etc.

Antes de continuar con nuestro análisis es necesario aclarar que trabajamos con distintos tipos de fuentes: por un lado, los Bandos Virreinales en donde desde el Estado se intenta compeler al trabajo, disciplinar la mano de obra, reducir y fijar el jornal que se paga, entre otras medidas, es decir el debería ser del proceso de trabajo y, por otro lado, trabajamos con las fuentes de la chacarita en las cuales se puede observar lo que realmente sucedia en este proceso. Esto nos permitió poder cruzar la información disponible y determinar si el ideal que partía desde los Bandos se llevaban a la práctica en una situación concreta.

Con relación al primer grupo de medidas vimos que la chacra no tiene dificultad en proveerse de peones libres, pero cuando tiene la posibilidad de recurrir al Estado lo hace y utiliza trabajo compulsivo, prisioneros que no fueron utilizados solamente para la cosecha sino también para realizar otro tipo de actividades como hemos visto. La combinación de la utilización de distintos tipos de explotación de la mano de obra -esclava, peones libres y peones compulsivos- nos muestra una yuxtaposición de estas formas de acceder al trabajo. Hay que remarcar que la utilización de peones compulsivos no significó mano de obra gratis sino que se les pago por el trabajo realizado. Tal como lo explica Chorroarin:

"...pues asi como no es justo hacerles trabajar gratuita.te, tampoco lo es q.e se aprecie su trabajo en lo mismo q.e pueda apreciarse el de los naturales..." 44

visto por sus empleadores y que -dado el alto costo del combustible- los hombres solteros comian pocas comidas preparadas y que éstas eran consumidas en el momento en que estaban trabajando. Johnson (1992: 180-81).

44 AGN, IX, 7-3-5, f. 298v. 
Acá podemos observar que este tipo de trabajo compulsivo no era solamente a "ración y sin sueldo" sino que se hace la diferencia entre naturales y extranjeros -que en este caso además de ser portugueses son prisioneros- distinción que se observa en el distinto monto del jornal pagado que era de 4 reales, tal como lo fijaba el Bando, pero que ya no es para los mejores peones porque el resto de éstos cobran entre 5 y 6 reales.

En cuanto al segundo grupo no encontramos ningún indicio en relación con lo que sucedía con los juegos, si eran permitidos ó no; ó, sí simplemente eran tolerados. Podemos pensar, en cambio, que podrían llegar a ser una de las causas de ausencia de los peones en un determinado momento de la jornada laboral. Las cuentas de la chacra son muy específicas al contabilizar el tiempo trabajado por los peones: hasta el almuerzo, hasta el mediodía, hasta la tarde. Al observar los Bandos vimos que la prohibición de los juegos era para que los peones no abandonen el trabajo, tal como lo marca uno de los Bandos: que se tome especial precaución en cuidar los márgenes y barracas de los ríos al mediodía porque en este momento se forman carreras de caballos y luego no se asiste al trabajo. Pero ésta es una hipótesis difícil de comprobar ya que no tenemos ningún tipo de referencia en las cuentas de la chacra que haga mención a que los peones se van por esta razón, pero sí pudimos observar, a partir del cuadro 3, que era normal que los peones no trabajen el día entero.

En relación con la prohibición de que los peones consuman alcohol -ya sea porque los compran en las pulperías o porque los labradores se los suministran-vemos que ésta no es observada por los administradores de la chacra, ya que en los años estudiados observamos que en los gastos de la siega también se contabilizan las compras de aguardiente para los peones.

El tercer grupo de medidas merece un análisis mucho más exhaustivo. Comenzaremos con la reiterada prohibición de entregar algún tipo de adelanto del salario/jornal: se pudo observar que en cuatro de los años estudiados existe esta costumbre, costumbre arraigada en la sociedad y que excede al caso estudiado ya que distintos trabajos, tanto para las chacras como para las estancias de ambas márgenes del Río de la Plata lo marcan, con lo cual es lícito pensar en que estos adelantos se constituyen como una forma de atraer mano de obra por parte de quienes la necesitan, aunque en algunos casos esto signifique perder, por parte de quien los contrata, ese adelanto otorgado porque el peón se va. Y, por otro lado, también podemos verlo como una estrategia por parte del peón rural que apro- 
vecha esta situación relativa de escasez de mano de obra y consigue que se le pague por adelantado por el trabajo que va a realizar, independientemente de que lo realice o le lleve una mayor cantidad de tiempo realizar el trabajo, a causa de fallas de días enteros o de una parte de la jornada laboral. De esta manera, el adelanto de salarios se presenta como una costumbre destinada a perdurar durante gran parte del siglo $\mathrm{XIX}^{45}$.

En este sentido también es importante destacar que a partir de 1791 -además de prohibir los adelantos de salarios- los Bandos estipulan que el peón que se retire antes de haber finalizado la siega pierda lo que ya había ganado ¿sucedió esto en la chacra? las fuentes nos muestran que sólo a partir de 1805 los peones tienden a quedarse trabajando durante el tiempo que dura la cosecha, para los años anteriores habíamos establecido que abandonaban el trabajo antes que finalice la cosecha y la chacra les paga por el tiempo que habían trabajado independientemente de lo que estipulaba el Bando.

Constantemente los bandos tratan de fijar el jornal que se pague en la siega y trata de equipararlo con el jornal que se paga en la ciudad a lo largo de todo el año. De un jornal de 2 reales que se intenta reducir y fijar en 1752, se pasa en 1787 (último bando que hace referencia a esto) a un jornal de 4 reales para "... los mejores peones q.e travajen en dhas. faenas... "46 y considera a estos jornales como "el acostumbrado", es decir, fijado no por la autoridad sino por la costumbre de la región. De hecho, se observó que en los años estudiados el jornal "acostumbrado " sufrió modificaciones y termina siendo de 5 reales para los días comunes. Esta situación de jornales en aumento, al igual que los adelantos salariales, nos marca que la chacra ante la necesidad de proveerse de peones y que no siempre puede recurrir a la utilización del trabajo compulsivo y la cantidad de esclavos que posee se manifiestan insuficientes en esta época del año, el pagar altos jornales actúa como atracción de mano de obra ${ }^{47}$, brazos que sí escasean en la época de la cosecha debido a que una

45 Cuando en 1856 se comienza a levantar las encuestas a los hacendados de la campaña boanaerense para la confección del Código Rural, estos manifiestan que terminar con esta costumbre sería satisfactorio pero que en la realidad era prácticamente imposible, ya que si no realizan estos adelantos se verían privados de peones para realizar los trabajos corrientes. Antecedentes y fundamentos del proyecto de Código Rural. (1864). Sobre otros aspectos de la vida rural en donde la costumbre es determinante en la conformación del Código Rural ver el trabajo de Fradkin (1997).

46 AGN, IX, 8-10-5, f. 14v. El subrayado es nuestro.

47 Esta situación no es específica de la chacra estudiado por nosotros ya que también se 
parte importante de pequeños productores, que a lo largo del año pueden utilizar al conchabo como un complemento de los ingresos familiares, se retiran a levantar sus propias sementeras. De ahi la necesidad de convocar a parte de la población de la ciudad desde peones hasta sastres y zapateros y paralizar los trabajos que en ella se realizan comúnmente a lo largo del año y ser más estrictos con la prohibición y reglamentación de los juegos ${ }^{48}$.

Veamos la reglamentación de los horarios de trabajo durante la siega. Aquí se puede observar mucho más cabalmente la costumbre y como ésta regula las condiciones sociales en que se realiza el proceso de trabajo. Como contrapartida a esta fijación de horarios se observaron las "obligaciones" por parte de quien los emplea: despertarlos con mate, darles habitación y comida. Estos estipendios se convierten en un salario indirecto con lo cual puede observarse una ventaja más al conchabarse en la época de la cosecha, al jornal más alto percibido integramente en plata hay que sumarle que al terminar el conchabo al peón le quedan íntegros sus reales percibidos. Esta reglamentación de horarios también sirve para que la chacra pueda determinar, según hasta que hora trabajo el peón, el jornal que le corresponde.

La siesta se manifiesta como una de las más importantes costumbres en la campaña en relación con el trabajo rural, ya que el hecho de no poder hacerla se traduce en el pago de un jornal más elevado. Jornal más elevado pero que siempre es de un real más, independientemente de cuanto sea el jornal. Como se observó hay una tendencia a aumentar el jornal hacia el final de los años estudiados pero por no dormir la siesta sigue siendo un real más. Este real que se paga de más actuaría como una compensación por hacer algo que no se acostumbra. Es decir, no está regulado por el mercado sino por la costumbre.

ha observado para otras unidades productivas como ser la estancia de las Bacas en la Banda Oriental. Gelman (1993a) y Salvatore y Browm (1993). Situación que también excede el marco temporal propuesto en este trabajo ya que va a perdurar en parte del siglo XIX. Por ejemplo en la época de Rosas, momento que se discute el monto del salario a pagar y que por lo general este es más alto de lo acostumbrado y continúa la preferencia, por parte del peón rural, por cobrar su salario íntegramente en plata, situación reconocida por Anchorena. Salvatore (1992).

48 Hay años en que no solamente se prohiben los juegos acostumbrados sino que también se suspenden diversiones atípicas, como ser en el verano de 1798 que se prohibe la elevación de un globo. Prohibición que se fundamenta en un posible incendio de las sementeras, como en que sería una excusa válida para que los peones abandonen el trabajo. AGN, IX, 19-7-8. 
Esta costumbre se extiende a que cuando se trabaja en día de fiesta -día en que no se realizan actividades rurales al igual que los domingos ${ }^{49}$ - como ser el $1^{\circ}$ de enero, se les abona un real extra al jornal acostumbrado.

\section{Algunas reflexiones finales}

A partir de esta aproximación a las características del trabajo rural en una chacra del ejido y al cruzamiento que se hizo con las normativas que parten desde el Estado Colonial pudimos observar características propias del proceso de trabajo y las condiciones en que éste se realiza.

Al analizar el trabajo y los trabajadores se observó que el salario en una chacra del ejido está altamente monetizado ya que éste es pagado en plata, salarios que van en aumento en años de escasez de ésta, tendencia que parece consolidarse al finalizar el período. También se pudo observar que los peones comienzan a quedarse más tiempo en su trabajo y la chacra baja el número de peones contratados y como contrapartida aumenta el número de esclavos como una forma de asegurarse mano de obra permanente.

Se observó la diversidad de tareas que realiza un peón rural en una chacra, por lo tanto estamos ante una mano de obra que utiliza los distintos tipos de trabajo y remuneraciones como estrategia para poder aumentar sus ingresos.

Pudimos observar que el trabajo estaba pautado y que tenía sus tiempos de trabajo y descanso, tiempos que son reglados por la autoridad y que respetan costumbres arraigadas en la sociedad -como ser la siesta- y que van a perdurar ${ }^{50}$. También marcamos como

49 Mayo (1995).

50 Para los años de 1820 un viajero inglés nos informa: "La siesta no está tan generalizada como antes", pero que sigue teniendo su importancia y que tiene su estación: el verano, desde los meses de octubre hasta la semana santa, en: Un inglés (1986: 72). Costumbre que también va a perdurar durante parte del siglo XIX. En el cuestionario que se envía a los Hacendados en 1856 para la confección del Código Rural, se les pregunta si convendria ordenar a quienes tienen animales en las chacras que también estén bajo el cuidado de un pastor "... durante la siesta, en los meses que esta se acostumbra... ". Antecedentes y fundamentos... (1864: 8). 
estas etapas de un día laboral se traducen en distintos montos de jornales debido a que no siempre los peones cumplían con la jornada de trabajo completa. Todo esto nos muestra como el trabajo, los tiempos del trabajo y el salario estaban pautados y moldeados por la costumbre. Costumbres que podrian haberse suprimido si aumentase la oferta de trabajo en la región estudiada, pero en condiciones de escasez estructural ${ }^{51}$ esto no era posible, motivo por el cual estas costumbres que regulan el proceso de trabajo se mantienen vigentes a lo largo del siglo XIX, aunque se haya intentado suprimirlas, ya sean desde el estado o por parte de labradores y estancieros.

Podemos decir que los Bandos no lograron sus objetivos cuando intentaron por un lado, reducir el jornal. Al contrario, hacia el final del período hay un aumento del jornal. Y, por otro lado, también fracasa al querer suprimir los adelantos salariales.

En contraposición a esta situación, cuando normalizan las costumbres, como ser los horarios de trabajo y de descanso, ejemplo máximo de esta situación el pago de un real extra por no dormir la siesta, observamos que desde el Estado se legitima esta costumbre.

Esto nos lleva a repensar las caracteristicas de los peones rurales al observar que tenían sus espacios de negociación y los hacían valer y que, al no existir una apropiación total de la tierra ni del trabajo del peón rural este puede prescindir del trabajo asalariado para poder subsistir y utiliza al conchabo como un complemento de sus ingresos.

51 Míguez (1997). 


\section{BIBLIOGRAFIA.}

ANTECEDENTES Y FUNDAMENTOS DEL PROYECTO DE CODIGO RURAL (1864), Bs. As., Imprenta de Buenos Aires.

AMARAL, Samuel (1987a). "Trabajo y trabajadores rurales en Buenos Aires a fines del siglo XVIII" en Anuario IEHS N², Tandil, pp 33-41.

AMARAL, Samuel (1987b). "Rural production and labour in late colonial Buenos Aires." en Journal of Latin American Studies, 19, London.

AZARA, Félix de (1943). Memoria sobre el estado rural del Río de la Plata y otros informes. Bs. As., Edit. Bajel.

CONCOLOCORVO (1946). El lazarillo de los ciegos caminantes. Bs. As., Espasa Calpe.

CHIARAMONTE, José Carlos (1984). Formas de sociedad y economía en Hispanoamérica. México, Enlace-Grijalbo.

FRADKIN, Raúl (1993). "Producción y arrendamiento en Buenos Aires del siglo XVIII: la hacienda de la Chacarita (1779-84). " en Raúl Fradkin (comp.): La historia agraria del Río de la Plata colonial. Los establecimientos productivos. Bs. As., CEAL, tomo II, pp 40-69.

FRADKIN, Raúl (1996). "'Según la costumbre del pays': costumbre y arriendo en Buenos Aires durante el siglo XVIII." en Boletín del Instituto de Historia Argentina y Americana 'Dr. E. Ravignani' N²11. Bs. As, pp. 39-64.

FRADKIN, Raúl (1997). "Entre la ley y la práctica: la costumbre en la campaña bonaerense de la primera mitad del siglo XIX." en Anuario IEHS N² 12. Tandil, pp 141-156.

GARAVAGLIA, Juan Carlos (1984). "Ecosistemas y tecnología agraria: elementos para una historia social de los ecosistemas agrarios rioplatenses." en Desarrollo Económico 28:112, Bs. As., pp 549-575.

GARAVAGLIA, Juan Carlos (1993). "Migraciones, estructuras familiares y vida campesina: 
Areco Arriba en 1815." en Juan Carlos Garavaglia y José Luis Moreno (comps.): Población, sociedad, familia y migraciones en el espacio rioplatense. Siglos XVIII y XIX. Bs. As., Edit. Cántaro, pp 149-187.

GARAVAGLIA, Juan Carlos (1995). "Tres estancias del sur bonaerense en un periodo de 'transición' (1790-1834)." en María Mónica Bjerg y Andrea Reguera (comps.): Problemas de la historia agraria. Nuevos debates y perspectivas de investigación. Tandil, IEHS, pp 79-123.

GELMAN, Jorge (1989). "Sobre esclavos, peones, gauchos y campesinos: el trabajo y los trabajadores en una estancia colonial rioplatense. " en Juan Carlos Garavaglia y Jorge Gelman: El mundo rural rioplatense a fines de la época colonial: estudios sobre producción y mano de obra. Bs. As., Edit. Biblos, pp 43-83.

GELMAN, Jorge (1992a). "Producción campesina y estancias en el Río de la Plata colonial. La región de Colonia a fines del siglo XVIII. " en Boletín del Instituto de Historia Argentina y Americana 'Dr. E. Ravignani' N²6. Bs. As., pp 41-65.

GELMAN, Jorge (1992b). "Mundo rural y mercados. Una estancia y las formas de circulación mercantil en la campaña rioplatense colonial" en Revista de Indias 195/196.

GELMAN, Jorge (1993a). "Una región y una chacra en la campaña rioplatense: las condiciones de la producción triguera a fines de la época colonial. " en Raúl Fradkin (comp.): La historia agraria del Río de la Plata colonial. Los establecimientos productivos. Bs. As., CEAL, tomo II, pp 7-39.

GELMAN, Jorge (1993b). "Familia y relaciones de producción en la campaña rioplatense coIonial. Algunas consideraciones desde la Banda Oriental." en Juan Carlos Garavaglia y José Luis Moreno (comps.): Población, sociedad, familia y migraciones en el espacio rioplatense. Siglos XVIII y XIX. Bs. As. , Edit. Cántaro, pp 75-103.

GILLESPIE, Alexandrer (1986). Buenos Aires y el Interior. Bs. As. , Hyspamérica.

JOHNSON, Lyman (1992). "La historia de precios de Buenos Aires durante el período virreinal." en Lyman Johnson y Enrique Tándeter (comps.): Economías coloniales. Precios y 
salarios en América Latina, siglo XVIII. Bs. As., FCE, pp 153-190.

HOBSBAWM, Eric (1977). Industria e Imperio. Barcelona, Edit. Ariel.

HOBSBAWM, Eric (1987). El mundo del trabajo. Estudios históricos sobre la formación y evolución de la clase obrera. Barcelona, Edit. Crítica.

MARTINEZ DOUGNAC, Gabriela (1996). "Justicia colonial, orden social y peonaje obligatorio." en Eduardo Azcuy Ameghino y otros: Poder terrateniente, relaciones de producción y orden colonial. Bs. As. , Fernando García Cambeiro, pp 185-225.

MAYO, Carlos (1984). "Estancia y peonaje en la región pampeana en la segunda mitad del siglo XVIII." en Desarrollo Económico 23:92, Bs. As. , pp 610-616.

MAYO, Carlos (1987). "Sobre peones, vagos y malentretenidos: el dilema de la economía rural rioplatense durante la época colonial." en Anuario IEHS N², Tandil, pp 25-32.

MAYO, Carlos (1991). Los betlemitas en Buenos Aires: convento, economía y sociedad. Sevilla.

MAYO, Carlos (1995). Estancia y sociedad en La Pampa, 1740-1820. Bs. As. , Edit. Biblos.

MIGUEZ, Eduardo (1997). "Mano de obra, población rural y mentalidades en la economía de tierras abiertas de la provincia de Buenos Aires. Una vez más, en busca del gaucho. " En Anuario IEHS $\mathrm{N}^{\circ} 12$, Tandil, pp 163-173.

PERRI, Gladys (1994). "Salario y mano de obra en una estancia colonial.", mimeo.

PERRI, Gladys (1995). "No sólo de carne vive el hombre... Una aproximación a las pautas alimentarias de la sociedad colonial. El caso del Real Colegio de San Carlos." " mimeo.

PERRI, Gladys (1998). "La 'Chacarita de los Colegiales'. Trabajo y producción en Buenos Aires a fines de la colonia." en Cuadernos de Trabajo. Luján, Depto. de Ciencias Sociales, UNLu. (en prensa). 
SALVATORE, Ricardo (1992). "Reclutamiento militar, disciplinamiento y proletarización en la era de Rosas." en Boletín del Instituto de Historia Argentina y Americana Dr. E. Ravignani' $N^{\circ}$ 5. Bs. As., pp 25-47.

SALVATORE, Ricardo y BROWN, Jonathan (1993). "Comercio y proletarización en la Banda Oriental tardocolonial: la estancia de las Vacas, 1791-1805." en Raúl Fradkin (comp.): La historia agraria del Río de la Plata colonial. Los establecimientos productivos. Bs. As. , CEAL, tomo I, pp 83-119.

THOMPSON, E.P. (1995). Costumbres en común. Barcelona, Edit. Crítica.

UN INGLES (1986). Cinco años en Buenos Aires, 1820-1825. Bs. As., Hyspamérica. 
CUADRO NO 1

BANDOS PUBLICADOS CON MOTIVO DE LA COSECHA DEL TRIGO, 1743-1805.

\begin{tabular}{|c|c|}
\hline MEDIDAS QUE SE TOMAN & $\begin{array}{l}\text { CANTIDAD } \\
\text { DE VECES }\end{array}$ \\
\hline \multicolumn{2}{|l|}{ A)- Convocatoria a la población. } \\
\hline Se convoca a indios, mestizos, negros y mulatos libres. & 1 \\
\hline Se convoca a indios, mulatos y negros libres. & 8 \\
\hline Se convoca a negros, mulatos, zapateros y sastres. & 18 \\
\hline Se convoca a todos los peones en general. & 4 \\
\hline $\begin{array}{l}\text { Se convoca a toda la gente de campo que no esté domiciliada } \\
\text { en la ciudad para que salga a la campaña. }\end{array}$ & 10 \\
\hline $\begin{array}{l}\text { Suspensión de trabajos en la ciudad: obrajes y obras públicas } \\
\text { para que los peones que allí trabajan partan a las chacras. }\end{array}$ & 30 \\
\hline Se limita la cantidad de trabajadores en los hornos de la ciudad. & 2 \\
\hline Se convoca a los vagabundos. & 13 \\
\hline Que el peón que vague por la campaña sea aprehendido. & 7 \\
\hline \multicolumn{2}{|l|}{ B)- Prohibición de juegos, diversiones y venta de alcohol. } \\
\hline Cierre de canchas en la ciudad. & 31 \\
\hline Prohibición de juegos en las chacras. & 26 \\
\hline Prohibición de todo tipo de juegos. & 7 \\
\hline Prohibición de venta de alcohol. & 4 \\
\hline \multicolumn{2}{|l|}{ C)- Reglamentación del trabajo. } \\
\hline Se reglamenta horario de trabajo. & 5 \\
\hline Prohibición de adelantos de salarios. & 8 \\
\hline $\begin{array}{l}\text { Que el peón que se retire antes de terminar la siega pierda } \\
\text { su jornal por el trabajo que ya realizó. }\end{array}$ & 7 \\
\hline Se fija el jornal. & 7 \\
\hline
\end{tabular}

Nota: cuando se repite un año es porque la primera fue publicada en enero y en diciembre de ese año ya se reglamenta la cosecha para el año entrante.

Fuente: Libros de Bandos. AGN, IX, 8-10-1; 8-10-2; 8-10-3; 8-10-4; 8-10-5; 8-10-7 y 8-10-8. 
CUADRO N' 2 I REGLAMENTACION DE LA JORNADA LABORAL

BANDO DEL 14-11-1777.

\begin{tabular}{|l|l|}
\hline \multicolumn{1}{|c|}{ HORA } & \multicolumn{1}{c|}{ DESCANSOS } \\
\hline $4 \mathrm{Hs}$. & Comienza la jornada laboral. Se sirve el primer mate. \\
\hline $5,30 \mathrm{Hs}$. & Se sirve el segundo mate. \\
\hline $6 \mathrm{Hs}$. & Se sirve el almuerzo. \\
\hline $7 \mathrm{Hs}$. & Se sirve el último mate de la mañana. \\
\hline $11,30 / 12 \mathrm{Hs}$. & Descanso. \\
\hline $12 \mathrm{Hs}$. & Se sirve la comida. \\
\hline $12 / 14 \mathrm{Hs}$. & Se retiran a dormir la siesta. \\
\hline $14 \mathrm{Hs}$. & Se los despierta con mate. \\
\hline $15,30 \mathrm{Hs}$. & Se sirve el mate. \\
\hline $17 \mathrm{Hs}$. & Se sirve el último mate de la tarde. \\
\hline $20 \mathrm{Hs}$. & Finaliza la jornada laboral. \\
\hline
\end{tabular}

Fuente: AGN, IX, 8-10-4.

CUADRO NO 3

FORMAS DE CONTABILIZAR EL TIEMPO DE TRABAJO DURANTE LA SIEGA.

\begin{tabular}{|c|l|c|l|}
\hline AÑO & \multicolumn{1}{|c|}{ TIEMPO TRABAJADO } & AÑO & \multicolumn{1}{c|}{ TIEMPO TRABAJADO } \\
\hline 1798 & $\begin{array}{l}\text { Día entero. } \\
\text { Hasta más de mediodía. } \\
\text { Mediodía. } \\
\text { Hasta el almuerzo. }\end{array}$ & 1802 & $\begin{array}{l}\text { Día entero. } \\
\text { Mediodía. }\end{array}$ \\
\cline { 2 - 4 } 1799 & $\begin{array}{l}\text { Día entero. } \\
\text { Hasta media tarde. } \\
\text { Mediodía. }\end{array}$ & 1803 & $\begin{array}{l}\text { Día entero. } \\
\text { Más un día incompleto. } \\
\text { Más parte de otro día. } \\
\text { Más un rato de otro día. }\end{array}$ \\
\hline 1800 & $\begin{array}{l}\text { Día entero. } \\
\text { Mediodía. } \\
\text { Más de media mañana. }\end{array}$ & 1805 & $\begin{array}{l}\text { Día entero. } \\
\text { Yun rato. }\end{array}$ \\
\hline 1801 & $\begin{array}{l}\text { Día entero. } \\
\text { Mediodía. }\end{array}$ & 1806 & $\begin{array}{l}\text { Día entero. } \\
\text { Mediodía. }\end{array}$ \\
\hline
\end{tabular}

Fuente: AGN, IX, 7-3-6. 